\title{
(6) OPEN ACCESS Are quitting-related cognitions and behaviours
predicted by proximal responses to plain packaging
with larger health warnings? Findings from a
national cohort study with Australian adult smokers
}

\author{
Emily Brennan, Sarah Durkin, Kerri Coomber, Meghan Zacher, Michelle Scollo, \\ Melanie Wakefield
}

- Additional material is published online only. To view please visit the journal online (http://dx.doi.org/10.1136/ tobaccocontrol-2014-052057).

Centre for Behavioural Research in Cancer, Cancer Council Victoria, Melbourne, Victoria, Australia

\section{Correspondence to} Professor Melanie Wakefield, Centre for Behavioural Research in Cancer, Cancer Council Victoria, 615 St Kilda Rd, Melbourne Vic 3004, Australia;

melanie.wakefield@cancervic. org.au

Received 25 September 2014 Revised 5 January 2015 Accepted 6 January 2015

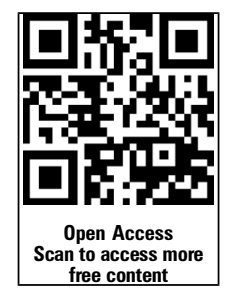

CrossMark

To cite: Brennan $E$, Durkin $\mathrm{S}$, Coomber $\mathrm{K}$, et al. Tob Control 2015;24: ii33-ii41.

\section{ABSTRACT}

Background Implementation of tobacco plain packaging (PP) with larger graphic health warnings (GHWs) in Australia had positive effects on responses reflecting the specific objectives of the PP policy and on follow-up quitting-related cognitions and behaviours. The aim of this study was to examine predictive relationships between these proximal and distal outcomes.

Methods A nationally representative sample of Australian adult cigarette smokers completed a baseline survey and a 1-month follow-up survey within the first year of policy implementation ( $($ weighted) $=3125)$. Logistic regression analyses tested whether baseline measures of cigarette appeal, GHW effectiveness, perceived harm and concern/enjoyment predicted each of seven follow-up measures of quitting-related cognitions and behaviours, adjusting for baseline levels of the outcome and covariates.

Results In multivariable models, we found consistent evidence that several baseline measures of GHW effectiveness positively and significantly predicted the likelihood that smokers at follow-up reported thinking about quitting at least daily, intending to quit, having a firm date to quit, stubbing out cigarettes prematurely, stopping oneself from smoking and having attempted to quit. Two of the quitting-related outcomes were also predicted by feeling more smoking-related concern than enjoyment. A smaller number of the appeal variables were prospectively associated with quitting-related outcomes, while believing that brands do not differ in harmfulness did not positively predict any outcomes. Conclusions These findings provide an initial insight into the pathways through which PP with larger GHWs may lead to changes in smoking behaviour. Future research should examine whether the effects are conditional on individual demographic and smoking characteristics.

\section{INTRODUCTION}

Drab dark brown plain packaging (PP) for tobacco products was first introduced in Australia from 1 October 2012 and fully implemented from 1 December 2012. ${ }^{2}$ At the same time, new and larger graphic health warnings (GHWs), covering $75 \%$ of the front of cigarette packs (up from $30 \%$ previously) and maintaining a coverage of $90 \%$ of the back, were also introduced onto packs. ${ }^{2}$ The specific objectives of the PP legislation were to: (A) reduce the appeal of tobacco products; (B) increase the effectiveness of the GHWs and (C) reduce the ability of packaging to mislead consumers about the harmful effects of smoking. More broadly though, and as part of a comprehensive tobacco control programme, the PP legislation aimed to reduce smoking rates by discouraging people from taking up smoking, encouraging smokers to quit and discouraging relapse. In a complementary way, the Information Standard that prescribed the new $\mathrm{GHWs}^{2}{ }^{3}$ aimed to increase consumer knowledge of the health effects resulting from tobacco use, ensure the continuing effectiveness of health warnings on the retail packaging of tobacco products, and by ensuring their effectiveness, encourage cessation and discourage initiation and relapse. ${ }^{3}$

Using data collected in continuous cross-sectional surveys conducted between April 2012 and November 2013 with a nationally representative sample of over 7000 Australian adult cigarette smokers (the National Plain Packaging Tracking Survey), Wakefield et $a l^{4}$ (this volume) demonstrated that the three specific objectives of the PP policy were largely achieved within the first year of implementation. Cigarette and cigarette packaging appeal reduced after implementation of the packaging changes. Smokers were more likely to report disliking the look of their pack, that their pack had lower appeal compared to a year ago, their cigarettes were of lower quality, less satisfying, and of lower value compared to a year ago, and that cigarette brands do not differ in prestige. ${ }^{4}$ Postimplementation, smokers were also more likely to notice the GHW first when they looked at their pack, to claim the GHWs had made them feel motivated to quit, and to report that they had tried to avoid the GHWs by deliberately concealing their pack and requesting a pack with a different health warning. Demonstrating the credibility of the GHWs, the proportion of smokers who did not believe that the dangers of smoking had been exaggerated remained stable at around two-thirds. Finally, there was some evidence that the packaging changes reduced the ability of tobacco packaging to mislead consumers. The proportion of smokers who believed brands do not differ in harm increased from before to after implementation. However, there was no change over time in the perception that cigarette brands differ in strength or that one's own cigarettes were more harmful compared to a year ago. ${ }^{4}$

Supplementing this evidence, Durkin et $a l^{5}$ (this volume) found increases in quitting-related cognitions and behaviours among adult cigarette smokers following implementation of PP with 
larger GHWs. The National Plain Packaging Tracking Survey was extended to a cohort study by recontacting smokers 1 month later, which allowed for comparisons in the rate of 1-month change in quitting-related outcomes for cohorts surveyed during the preimplementation, transition and postimplementation periods. Most notably, compared with smokers surveyed before the packaging changes, those who completed their follow-up survey after full implementation were more likely to report that in the past month they had concealed their pack, stubbed out cigarettes prematurely and attempted to quit. ${ }^{5}$

Although no research has yet specifically examined predictive relationships between proximal responses to the Australian packaging changes and subsequent quitting-related outcomes, it is reasonable to expect that these measures will be prospectively related. Cigarette packaging-as one of many forms of cigarette marketing-is known to play an important role in driving the initiation, continuation and cessation of smoking behaviour, ${ }^{6-11}$ and exposure to GHWs has been shown to increase quitting cognitions and attempts ${ }^{12}$ and even to reduce smoking prevalence. ${ }^{13}$ In the light of evidence that PP with larger GHWs had the desired effect on both the specific objectives of the PP legislation ${ }^{4}$ and also on a number of more distal outcomes, ${ }^{5}$ the aim of the current study was to investigate associations between these proximal and distal measures of effectiveness of the packaging changes. Specifically, we examined whether each of the variables that Wakefield et $a l^{4}$ used to measure the effectiveness of PP with larger GHWs and that were found to change in the expected direction following implementation prospectively predicted each of the quitting-related cognitions and behaviours examined by Durkin et $a l^{5}$ (thoughts about quitting, intentions to quit, pack concealment, stubbing out, stopping oneself from smoking and attempting to quit). Evidence of prospective relationships between these proximal and distal measures would shed light on the mechanisms through which PP with larger GHWs may contribute to quitting cognitions and behaviours.

\section{METHODS}

\section{Study design and procedure}

Using dual frame random digit dialling telephone surveys (response rate 57\%), we conducted a prospective cohort study in which respondents completed a follow-up interview approximately 1 month after baseline (median time to follow-up=29 days, range $=18-64$ days; mean retention rate per month $=83 \%$, range $=78 \%-87 \%)$. The study procedure is described in more detail elsewhere. ${ }^{4} 514$

\section{Sample}

For the purposes of this study, the sample was restricted to current smokers of factory-made or roll-your-own cigarettes (currently smoked daily or weekly, or smoked monthly or less-than-monthly but self-identified as a smoker rather than as an ex-smoker) who completed their baseline and follow-up surveys during the first year of implementation of the packaging changes; that is, after 1 December 2012 and before 30 November 2013 (prior to implementation of the $12.5 \%$ tax increase for tobacco products that occurred in Australia on 1 December 2013). We further limited the sample to those who had valid data on all covariates ( $>98 \%$ of cases). In total, within this period, 4240 (weighted; n(unweighted) =4229) cigarette smokers completed their baseline survey and 3125 (weighted; n(unweighted)=3081) of these also completed the follow-up survey.

We used two analytical samples. First, cigarette smokers at baseline who continued to be cigarette smokers at follow-up ('continuing cigarette smokers'; $\mathrm{n}$ (weighted)=2948; n (unweighted) $=2907$ ) were used in models predicting all outcomes except for quit attempts. Second, cigarette smokers at baseline who completed the follow-up survey ('baseline cigarette smokers'; n(weighted) $=3125 ;$ n (unweighted $)=3081$ ) were used in models predicting the likelihood that smokers had attempted to quit in the month between the baseline and follow-up surveys.

\section{Outcome measures}

\section{Quitting-related cognitions}

As described by Durkin et $a l,{ }^{5} 14$ in the baseline and follow-up interviews we measured the occurrence of thoughts about quitting in the past week (thought about quitting once or several times a day vs thought about quitting only once every few days, once or not at all). Intentions to quit were measured by asking respondents whether they intended to quit in the next month (yes vs no or do not know/cannot say), and by further asking those who intended to quit if they had set a firm date to quit in the next month (yes vs no or do not know/cannot say (including those who did not intend to quit)).

\section{Pack concealment and microindicators of concern}

At baseline and follow-up, we asked respondents to report how frequently in the past month they had concealed or covered their cigarette packs, stubbed out a cigarette because they thought about the harms of smoking, and had stopped themselves from smoking when they had an urge to smoke. Response options for all three measures were dichotomised to allow us to compare those who had engaged in the behaviour several or many times in the past month with those who had performed the behaviour never or just once or twice..$^{5} 14$

\section{Quit attempts}

At baseline, respondents were asked whether they had ever attempted to quit smoking and, if so, how long it had been since their last quit attempt. At follow-up, those who had been current smokers at baseline were asked if they were still smoking and, if so, whether they had made any attempts to quit smoking over the past month. Our measure of attempts to quit between baseline and follow-up included all baseline smokers who had made a quit attempt, including those who were still smoking and those who were quit at follow-up (ie, had made a successful quit attempt). Given the evidence that the recency of previous quit attempts is an important predictor of subsequent quit attempts, ${ }^{15}$ we controlled for smokers' recent quitting history using a five-category measure: never tried to quit; tried to quit more than 12 months ago; tried to quit between 6 and 12 months ago; tried to quit between 2 and 6 months ago or tried to quit within the past month.

\section{Predictor variables}

Appeal variables

As predictor variables, we used six appeal-related variables that changed from preimplementation to postimplementation in a direction consistent with the aims of the PP legislation. ${ }^{4}$ At baseline, respondents: (1) indicated whether they liked the look of their current cigarette pack (somewhat or strongly disagreed that they liked their pack vs all other responses); rated their current cigarettes as being higher, lower or about the same compared to a year ago in terms of (2) appeal of the packaging, (3) quality, (4) satisfaction and (5) value for money (lower compared to a year ago vs all others); and (6) reported whether they believed there are differences between brands in prestige (no vs yes/do not know). ${ }^{14}$ 
Health warning effectiveness variables

Five GHW effectiveness variables changed in a direction consistent with the aims of the PP legislation. ${ }^{4}$ At baseline, respondents indicated: (1) whether they usually noticed the GHW first when looking at a pack of cigarettes (vs noticing other aspects of the pack first, such as branding); (2) whether they agreed or disagreed that the dangers of smoking have been exaggerated (somewhat/strongly disagree vs neutral and agree responses); (3) whether the health warnings made them feel more motivated to quit (much more motivated vs all others); and whether they had tried to avoid the GHWs in the past month by (4) covering up or concealing their pack or putting their cigarettes in another container (several or many times vs other responses) or (5) requesting a pack with a different health warning on it (yes vs no). ${ }^{14}$

\section{Perceived harm variables}

The one harm perception variable that changed in a direction consistent with the aims of $\mathrm{PP}^{4}$ was also included. Smokers were asked whether they believed that some cigarette brands are more harmful than others (no vs yes/do not know). ${ }^{14}$

\section{Balance between enjoyment and concern}

Deciding to give up smoking can be conceptualised as a struggle between factors that enhance the enjoyment of smoking and factors that increase concern about the impact of smoking. ${ }^{16}$ Although reducing enjoyment and increasing concern were not the primary objectives of the PP legislation, it is likely that these two constructs would be influenced by cigarette appeal, GHW effectiveness and perceived harm, and in combination, they have been found to predict quitting-related outcomes. ${ }^{17}$ We created a baseline measure of the balance between enjoyment and concern from items measuring how often respondents had thought about how much they enjoy smoking in the past month: $1=$ never; $2=$ once or twice; $3=$ several times or $4=$ many times, and how concerned they were that smoking may affect or has already affected their own personal health: $1=$ not at all; $2=$ a little concerned; $3=$ somewhat concerned; $4=$ very concerned and $5=$ extremely concerned. We then standardised these two variables using $\mathrm{z}$-scores and subtracted the standardised 'concern' score from the standardised 'enjoyment' score. After inspecting a histogram of resulting scores to identify natural cut points, we constructed a categorical variable with three levels: more enjoyment $(<1 \mathrm{SD}$ below the mean); balanced between enjoyment and concern; and more concern $(>1$ SD above the mean).

\section{Covariates}

At baseline, respondents reported their sex, age and highest level of education. Socioeconomic status was measured using the Australian Bureau of Statistics' Index of Socio-Economic Disadvantage, using the 2011 census data of the postcode area in which respondents resided. ${ }^{18}$ Respondents also reported the number of cigarettes smoked per day and the time to first cigarette, which were combined into the Heaviness of Smoking Index. ${ }^{19}$

We sourced records from ACNielsen of monthly Target Audience Rating Points (TARPs) for adults aged 18 and above for all antismoking campaigns aired on television over the survey period. TARPs represent potential exposure to advertising. Consistent with previous research which has shown that effects of antismoking advertising occur within 3-month periods, ${ }^{20} 21$ we used a cumulative sum of the previous 3 months' TARPs, based on the date of follow-up. Cigarette costliness in the month of follow-up interview was calculated as the ratio of the average recommended retail price (RRP) of the top 10 brands (weighted by market share) to the average weekly earnings in the respondents' state of residence. ${ }^{22}$ We controlled for percentage change in costliness over the past 3 months, in those survey months in which RRPs increased due to excise/ customs duty indexation ${ }^{14}$ : percentage change in costliness in February 2013, $\mathrm{M}=3.29, \mathrm{SE}=0.05$; August 2013, $\mathrm{M}=0.42$, $\mathrm{SE}=0.08$.

\section{Statistical analysis}

The baseline sample was weighted using a design weight and a poststratification weight, accounting for telephony status (landline or mobile), gender, age by education, and state of residence. $^{4} 14$ The follow-up sample was weighted using a longitudinal weight, derived from an adjustment to the baseline weighting variable, which accounted for each participant's probability of being retained in the follow-up sample..$^{514}$

We conducted a series of initial logistic regression models to examine the association between each predictor and each outcome (ie, one model per predictor/outcome). When more than one significant predictor $($ at $\mathrm{p}<0.05)$ of an outcome was identified, we then conducted a multivariable model that included all predictors associated with the outcome at $\mathrm{p}<0.05$, so as to identify the strongest independent predictors. We conducted initial and multivariable models that were unadjusted (presented in appendix A of the online supplementary material) and adjusted for the covariates described above as well as the date of the follow-up survey and the number of days between surveys (results from adjusted models are presented here in tables and text). Unadjusted and adjusted models both controlled for the baseline level of the outcome variable.

We conducted two sets of sensitivity testing. First, to examine the possibility that associations between the predictors and the outcomes were influenced by the anticipation of the $12.5 \%$ tax increase on 1 December 2013 rather than the packaging changes, we repeated all adjusted analyses excluding respondents who were followed up in November 2013 (n(weighted) $=297$ baseline cigarette smokers and 284 continuing cigarette smokers). Second, previous research has indicated that interest in quitting tends to be lower in the last 3 weeks of December and higher in the first 2 weeks of January. ${ }^{23}$ As none of the respondents in this study were followed up in December, we repeated all adjusted analyses including an indicator variable to capture the January seasonality effect.

All analyses were conducted in Stata V.12.1, ${ }^{24}$ adjusting for the effects of sample weighting on parameter estimates and SEs. In addition, an unconditional approach was used to limit the sample as appropriate for each set of analyses, ensuring correct estimation of the SEs. Cases that had missing data on outcome variables, the baseline versions of these variables and predictor variables (typically $<5 \%$ combined) were deleted listwise from each model.

\section{RESULTS}

Table 1 presents sample characteristics, and descriptive statistics for the predictor variables and outcome variables.

\section{Predicting quitting-related cognitions}

Among continuing cigarette smokers at follow-up, 36.5\% reported that they had thought about quitting at least daily in the past week. Table 2 shows that, in the initial models, cigarette smokers who at baseline disliked the look of their pack were significantly more likely to report thinking about quitting at least daily at follow-up, compared with those who did not dislike the 
Table 1 Sample characteristics, predictor variables at baseline, and outcome variables at follow-up for continuing and baseline cigarette smokers at follow-up

\begin{tabular}{|c|c|c|}
\hline & $\begin{array}{l}\text { Continuing cigarette smokers } \\
\text { at follow-up* } \\
\text { ( } \mathrm{N}=2948)\end{array}$ & $\begin{array}{l}\text { Baseline cigarette smokers } \\
\text { at follow-upt } \\
\text { (N=3125) }\end{array}$ \\
\hline Sample characteristics at baseline and covariates & $\%$ & $\%$ \\
\hline \multicolumn{3}{|l|}{ Sex } \\
\hline Males & 54.7 & 55.1 \\
\hline Females & 45.3 & 44.9 \\
\hline \multicolumn{3}{|l|}{ Age (years) } \\
\hline $18-29$ & 27.3 & 28.1 \\
\hline 30-49 & 46.7 & 46.4 \\
\hline $50-69$ & 25.9 & 25.6 \\
\hline \multicolumn{3}{|l|}{ Highest level of education } \\
\hline Less than high school & 33.4 & 32.9 \\
\hline Completed high school/some tertiary & 54.4 & 54.3 \\
\hline Tertiary or above & 12.2 & 12.8 \\
\hline \multicolumn{3}{|l|}{ Socioeconomic status } \\
\hline Low & 41.4 & 41.0 \\
\hline Mid & 41.6 & 42.0 \\
\hline \multirow[t]{2}{*}{ High } & 17.0 & 17.0 \\
\hline & Mean (SE) & Mean (SE) \\
\hline Heaviness of smoking index $(0-6)$ & $2.23(0.04)$ & $2.17(0.04)$ \\
\hline Days between baseline and follow-up survey & $30.08(0.10)$ & $30.11(0.10)$ \\
\hline Antismoking advertising in past 3 months & $1447(17.2)$ & $1446(16.8)$ \\
\hline Predictor variables at baseline & $\%$ & $\%$ \\
\hline \multicolumn{3}{|l|}{ Appeal variables } \\
\hline Dislikes pack & 79.9 & 79.5 \\
\hline Lower pack appeal & 48.9 & 48.7 \\
\hline Lower quality & 26.3 & 26.1 \\
\hline Lower satisfaction & 20.6 & 20.5 \\
\hline Lower value for money & 55.1 & 55.0 \\
\hline Believes brands do not differ in prestige & 48.2 & 48.0 \\
\hline \multicolumn{3}{|l|}{ Health warning effectiveness variables } \\
\hline Notices GHW first when looking at pack & 65.9 & 66.1 \\
\hline Does not believe dangers of smoking are exaggerated & 62.1 & 62.9 \\
\hline Attributes much more motivation to quit to GHWs & 12.4 & 13.3 \\
\hline Concealed or covered pack in past month & 23.0 & 23.0 \\
\hline Requested different GHW in past month & 8.9 & 9.1 \\
\hline \multicolumn{3}{|l|}{ Perceived harm variables } \\
\hline Believes brands do not differ in harmfulness & 67.8 & 67.3 \\
\hline \multicolumn{3}{|l|}{ Balance between enjoyment and concern } \\
\hline More enjoyment & 16.4 & 21.0 \\
\hline Balance & 58.5 & 55.2 \\
\hline More concern & 23.0 & 21.7 \\
\hline \multicolumn{3}{|l|}{ Outcome variables at follow-up } \\
\hline \multicolumn{3}{|l|}{ Quitting-related cognitions } \\
\hline Daily thoughts about quitting in past week & 36.5 & - \\
\hline Intend to quit in next month & 36.5 & - \\
\hline Firm date to quit in next month & 6.7 & - \\
\hline \multicolumn{3}{|l|}{ Pack concealment and microindicators of concern } \\
\hline Concealed or covered pack several or many times in past month & 19.5 & - \\
\hline Stubbed out several or many times in past month & 26.7 & - \\
\hline Stopped oneself from smoking several or many times in past month & 37.8 & - \\
\hline \multicolumn{3}{|l|}{ Quitting behaviours } \\
\hline Attempted to quit in past month & - & 23.6 \\
\hline
\end{tabular}

All data are weighted using longitudinal weights. Owing to rounding and missing data on outcome variables (including do not know, not applicable and refused responses), percentages may not sum to 100 . Descriptive data for the covariate capturing percentage change in cigarette costliness are presented in text.

*Sample used in analyses predicting daily thoughts about quitting, intentions to quit in next month, firm date to quit in next month, pack concealment, stubbing out and stopping oneself from smoking.

tSample used in analyses predicting attempts to quit in past month.

GHW, graphic health warning. 
look of their pack. Similarly, smokers who at baseline reported less satisfaction from their cigarettes compared to a year ago were more likely to report daily thoughts about quitting. Quitting thoughts were also significantly and positively predicted by noticing GHWs first, disagreeing that the dangers of smoking have been exaggerated, attributing motivation to quit to the GHWs and pack concealment. Quitting thoughts were unrelated to believing brands do not differ in harm, but were positively predicted by feeling more concern than enjoyment. Entering all of these significant predictors into a multivariable model changed the pattern of results only slightly: the predictive effects of noticing GHWs first and feeling more concern than enjoyment were no longer statistically significant (table 2).

Among continuing cigarette smokers at follow-up, 36.5\% intended to quit within the next month. No appeal variables predicted intentions, but in the initial models, smokers were significantly more likely to intend to quit if at baseline they reported noticing GHWs first, disagreeing that the dangers of smoking have been exaggerated and attributing motivation to quit to the GHWs. Intentions were also significantly and positively predicted by feeling more concern than enjoyment. In the multivariable model, the predictive effect of all variables except noticing GHWs first remained statistically significant (table 2).

Smokers who intended to quit were further asked if they had set a firm date to quit, and $6.7 \%$ of all continuing smokers reported that they had. Having a firm date to quit was significantly and positively predicted in the initial models by GHW noticeability, disagreeing that the dangers of smoking have been exaggerated and attributing motivation to quit to the GHWs. The pattern and significance of findings remained in the multivariable model (table 2).

\section{Predicting pack concealment and microindicators of concern}

Among continuing cigarette smokers at follow-up, 19.5\% reported that they had concealed or covered up their cigarette pack several or many times in the past month. None of the predictor variables were significantly associated with pack concealment in the initial models, so no multivariable model was conducted (table 3).

Just over one-quarter (26.7\%) of continuing smokers reported that they had stubbed out a cigarette at least several times in the past month. In the initial models, stubbing out was significantly and positively predicted by lower satisfaction compared to a year ago; by GHW noticeability, attributing motivation to quit, pack concealment and requesting a different GHW; and by feeling more concern than enjoyment. The multivariable model showed a similar pattern of results (table 3 ).

More than two-thirds (37.8\%) of continuing cigarette smokers reported that they had stopped themselves from having a cigarette at least several times in the past month. In the initial models, stopping smoking was significantly and positively predicted by lower satisfaction compared to a year ago, disagreeing that the dangers of smoking have been exaggerated, attributing motivation to quit to GHWs and feeling more concern than enjoyment. In the multivariable model, the predictive effects of attributing motivation to quit to GHWs and feeling more concern than enjoyment were no longer statistically significant (table 3 ).

\section{Predicting quit attempts}

Overall, 23.6\% of baseline cigarette smokers had made an attempt to quit in the month between their baseline and follow-up survey (including those who had relapsed to smoking and those who were still quit at follow-up). In the initial models, quit attempts were significantly predicted by one appeal variable: unexpectedly, smokers who believed that brands do not differ in prestige were significantly less likely to have attempted to quit, although this effect did not remain statistically significant in the multivariable model. In contrast, smokers were more than twice as likely to have attempted if they attributed motivation to quit to GHWs, and if they had requested a pack with a different GHW, and both of these effects remained significant in the multivariable model. Finally, quit attempts were also predicted by the perceived harm variable. Unexpectedly, smokers who believed that brands do not differ in harmfulness were less likely to have attempted to quit at follow-up, although again this effect did not remain statistically significant in the multivariable model (table 4).

\section{Sensitivity testing}

Appendix A in the online supplementary material presents results for initial and multivariable models that were unadjusted for covariates, and shows that there was very little difference in the overall pattern of findings. Online supplementary appendices $B$ and $C$ show that the two sets of sensitivity testing also did not change the overall pattern of results.

\section{DISCUSSION}

We found consistent evidence in the multivariable models that indicators of GHW effectiveness were prospectively related to 1-month changes in several of the quitting-related outcomes. In particular, smokers were more likely to have engaged in four of the seven quitting cognitions and behaviours if they did not believe that the dangers of smoking are exaggerated (an indicator of GHW credibility), and they were significantly more likely to have engaged in five of the seven outcomes if they attributed motivation to quit to GHWs. Consistent with evidence of the role that GHWs play in promoting smoking cessation ${ }^{12} 132526$ and experimental research demonstrating that GHWs are more effective when they appear on plain packs, ${ }^{27-31}$ these findings suggest that the short-term increases in quitting-related intentions and behaviours observed in Australia following implementation of PP with larger $\mathrm{GHWs}^{5}$ are most likely explained by smokers' responses to the new and larger GHWs.

In the multivariable models, we also found that smokers who experienced more concern than enjoyment from their smoking were significantly more likely to have an intention to quit, and to report stubbing out. In contrast, the belief that brands do not differ in harmfulness was not significantly associated with any of the outcomes, and only some of the appeal variables were prospectively related to quitting-related cognitions and behaviours: smokers who at baseline disliked the look of their cigarette pack were more likely to report daily thoughts about quitting, and those who reported lower satisfaction were more likely to report daily thoughts about quitting, stubbing out and stopping oneself from smoking.

Providing further evidence that GHW effectiveness may be the primary driver of the observed increases in quitting cognitions and behaviours among adult smokers, the initial models revealed an additional four significant effects of appeal, perceived harm and enjoyment/concern variables that did not remain statistically significant once entered into the multivariable model with the GHW effectiveness variables. Besides this small number of effects though, the pattern of results (including the magnitude of effects) was largely the same across the initial and multivariable models-particularly for the GHW effectiveness variables-indicating that the various predictors explain unique variance in the outcomes. In particular, results from the multivariable models predicting quitting thoughts and the two microindicators of concern suggest that the effect of lower 
Table 2 Associations between appeal, health warning effectiveness, perceived harm and enjoyment/concern variables measured at baseline, and quitting-related cognitions measured at 1-month follow-up among continuing cigarette smokers

\begin{tabular}{|c|c|c|c|c|c|c|}
\hline & \multicolumn{2}{|c|}{ Daily thoughts about quitting in past week } & \multicolumn{2}{|c|}{ Intend to quit in next month } & \multicolumn{2}{|c|}{ Firm date to quit in next month } \\
\hline & $\begin{array}{l}\text { Initial models } \\
(\mathrm{N}=2565 \text { to } 2915)\end{array}$ & $\begin{array}{l}\text { Multivariable model } \\
(\mathrm{N}=2571)\end{array}$ & $\begin{array}{l}\text { Initial models } \\
\text { ( } \mathrm{N}=2584 \text { to } 2995)\end{array}$ & $\begin{array}{l}\text { Multivariable model } \\
(\mathrm{N}=2831)\end{array}$ & $\begin{array}{l}\text { Initial models } \\
(\mathrm{N}=2584 \text { to } 2995)\end{array}$ & $\begin{array}{l}\text { Multivariable model } \\
(\mathrm{N}=2883)\end{array}$ \\
\hline & OR (95\% Cl) & OR $(95 \% \mathrm{Cl})$ & OR $(95 \% \mathrm{Cl})$ & OR $(95 \% \mathrm{Cl})$ & OR $(95 \% \mathrm{Cl})$ & OR $(95 \% \mathrm{Cl})$ \\
\hline \multicolumn{7}{|l|}{ Appeal variables } \\
\hline Dislikes pack & $1.59 * *(1.17$ to 2.16$)$ & $1.38^{*}(1.00$ to 1.89$)$ & $1.16(0.85$ to 1.57$)$ & - & 1.01 (0.62 to 1.63$)$ & - \\
\hline Lower pack appeal & $1.01(0.81$ to 1.26$)$ & - & 1.00 (0.80 to 1.25$)$ & - & 1.19 (0.82 to 1.73$)$ & - \\
\hline Lower quality & $1.26(1.00$ to 1.59$)$ & - & 1.00 (0.78 to 1.27$)$ & - & 0.96 (0.65 to 1.41$)$ & - \\
\hline Lower satisfaction & $1.46^{* *}(1.13$ to 1.88$)$ & $1.49 * *(1.14$ to 1.95$)$ & 1.19 (0.92 to 1.53$)$ & - & $1.33(0.90$ to 1.97$)$ & - \\
\hline Lower value for money & $1.12(0.91$ to 1.38$)$ & - & 1.01 (0.81 to 1.24$)$ & - & 1.06 (0.76 to 1.48$)$ & - \\
\hline Believes brands do not differ in prestige & $0.90(0.72$ to 1.11$)$ & - & 1.08 (0.87 to 1.33$)$ & - & 0.93 (0.65 to 1.32$)$ & - \\
\hline \multicolumn{7}{|l|}{ Health warning effectiveness variables } \\
\hline Notices GHW first when looking at pack & $1.37^{* *}(1.10$ to 1.72$)$ & 1.07 (0.84 to 1.35$)$ & $1.32 *(1.06$ to 1.64$)$ & 1.20 (0.95 to 1.50$)$ & $1.82^{* *}(1.23$ to 2.71$)$ & $1.60 *(1.06$ to 2.40$)$ \\
\hline Does not believe dangers of smoking are exaggerated & $1.72^{* * *}(1.38$ to 2.14$)$ & $1.69^{* * *}(1.33$ to 2.15$)$ & $1.48^{* * *}(1.19$ to 1.84$)$ & $1.39^{* *}(1.11$ to 1.75$)$ & $1.64^{*}(1.12$ to 2.40$)$ & $1.50 *(1.02$ to 2.23$)$ \\
\hline Attributes much more motivation to quit to GHWs & $2.72^{* * *}(1.90$ to 3.90$)$ & $2.52^{* * *}(1.71$ to 3.73$)$ & $1.71^{* * *}(1.24$ to 2.36$)$ & $1.48^{*}(1.06$ to 2.07$)$ & $2.00^{* *}(1.29$ to 3.11$)$ & $1.81 * *(1.17$ to 2.78$)$ \\
\hline Concealed or covered pack in past month & $1.61^{* * *}(1.28$ to 2.03$)$ & $1.46^{* *}(1.14$ to 1.88$)$ & $1.03(0.82$ to 1.30$)$ & - & 0.91 (0.61 to 1.36$)$ & - \\
\hline Requested different GHW in past month & $1.00(0.68$ to 1.48$)$ & - & 1.26 (0.86 to 1.85$)$ & - & 0.95 (0.53 to 1.68$)$ & - \\
\hline \multicolumn{7}{|l|}{ Perceived harm variables } \\
\hline Believes brands do not differ in harmfulness & 0.83 (0.66 to 1.04$)$ & - & 0.86 (0.68 to 1.08 ) & - & 0.89 (0.61 to 1.29$)$ & - \\
\hline \multicolumn{7}{|l|}{ Balance between enjoyment and concern } \\
\hline More enjoyment & 1.00 & 1.00 & 1.00 & 1.00 & 1.00 & - \\
\hline Balance & $1.19(0.88$ to 1.60$)$ & 1.02 (0.74 to 1.39$)$ & 1.34 (0.98 to 1.82$)$ & 1.21 (0.89 to 1.65$)$ & 0.93 (0.57 to 1.52$)$ & \\
\hline More concern & $1.59^{* *}(1.13$ to 2.24$)$ & 1.25 (0.87 to 1.81$)$ & $2.29 * * *(1.61$ to 3.25$)$ & $1.96^{* * *}(1.37$ to 2.82$)$ & 1.30 (0.76 to 2.23 ) & \\
\hline
\end{tabular}

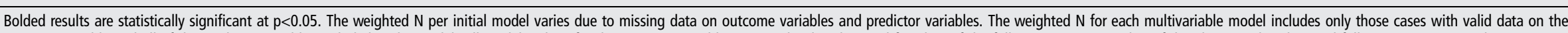

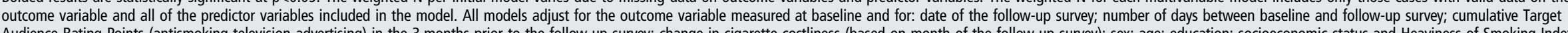
Audience Rating Points (antismoking television advertising) in the 3 months prior to the follow-up survey; change in cigarette costliness (bas (measured at baseline). - Predictor variable not included in multivariable model due to non-significant (at $p<0.05$ ) association with outcome variable in initial model.

GHW, graphic health warning. 
Table 3 Associations between appeal, health warning effectiveness, perceived harm and enjoyment/concern variables measured at baseline, and pack concealment and microindicators of concern measured at 1-month follow-up among continuing cigarette smokers

\begin{tabular}{|c|c|c|c|c|c|}
\hline & \multirow{2}{*}{$\begin{array}{l}\text { Concealed or covered } \\
\text { pack several or many } \\
\text { times in past month } \\
\text { Initial models ( } \mathrm{N}=2568 \text { to } \\
2899 \text { ) }\end{array}$} & \multicolumn{2}{|c|}{$\begin{array}{l}\text { Stubbed out several or many times in past } \\
\text { month }\end{array}$} & \multicolumn{2}{|c|}{$\begin{array}{l}\text { Stopped oneself from smoking several or many } \\
\text { times in past month }\end{array}$} \\
\hline & & $\begin{array}{l}\text { Initial models ( } N=2566 \\
\text { to 2919) }\end{array}$ & $\begin{array}{l}\text { Multivariable model } \\
(\mathrm{N}=2559)\end{array}$ & $\begin{array}{l}\text { Initial models ( } N=2567 \\
\text { to } 2913 \text { ) }\end{array}$ & $\begin{array}{l}\text { Multivariable model } \\
(\mathrm{N}=2770)\end{array}$ \\
\hline & OR $(95 \% \mathrm{Cl})$ & OR (95\% Cl) & OR $(95 \% \mathrm{Cl})$ & OR (95\% Cl) & OR $(95 \% \mathrm{Cl})$ \\
\hline \multicolumn{6}{|l|}{ Appeal variables } \\
\hline Dislikes pack & 1.05 (0.69 to 1.61$)$ & 1.40 (1.00 to 1.95$)$ & - & $1.13(0.85$ to 1.50$)$ & - \\
\hline Lower pack appeal & 1.25 (0.94 to 1.66$)$ & 1.11 (0.88 to 1.40$)$ & - & 1.17 (0.95 to 1.44$)$ & - \\
\hline Lower quality & 1.07 (0.80 to 1.41$)$ & 1.12 (0.88 to 1.43 ) & - & 1.07 (0.86 to 1.33$)$ & - \\
\hline Lower satisfaction & 1.07 (0.78 to 1.45$)$ & $1.36^{*}(1.05$ to 1.77$)$ & $1.41 *(1.07$ to 1.84$)$ & $1.36^{*}(1.07$ to 1.72$)$ & $1.38^{* *}(1.09$ to 1.76$)$ \\
\hline Lower value for money & $0.94(0.71$ to 1.23$)$ & 0.94 (0.76 to 1.18$)$ & - & $1.10(0.90$ to 1.35$)$ & - \\
\hline $\begin{array}{l}\text { Believes brands do not } \\
\text { differ in prestige }\end{array}$ & 0.93 (0.71 to 1.21$)$ & 1.08 (0.86 to 1.35$)$ & - & 0.99 (0.82 to 1.21$)$ & - \\
\hline \multicolumn{6}{|c|}{ Health warning effectiveness variables } \\
\hline $\begin{array}{l}\text { Notices GHW first when } \\
\text { looking at pack }\end{array}$ & 0.95 (0.72 to 1.26$)$ & $1.51^{* * *}(1.19$ to 1.91$)$ & $1.46^{* *}(1.13$ to 1.88$)$ & 1.09 (0.89 to 1.33 ) & - \\
\hline $\begin{array}{l}\text { Does not believe dangers } \\
\text { of smoking are } \\
\text { exaggerated }\end{array}$ & 0.91 (0.70 to 1.18 ) & 1.14 (0.91 to 1.42 ) & - & $1.31 * *(1.07$ to 1.60$)$ & $1.35^{* *}(1.09$ to 1.67$)$ \\
\hline $\begin{array}{l}\text { Attributes much more } \\
\text { motivation to quit to } \\
\text { GHWs }\end{array}$ & 1.26 (0.84 to 1.89 ) & $1.93^{* * *}(1.38$ to 2.71$)$ & $1.75^{* *}(1.23$ to 2.48$)$ & $1.39^{*}(1.02$ to 1.90$)$ & 1.32 (0.95 to 1.83 ) \\
\hline $\begin{array}{l}\text { Concealed or covered pack } \\
\text { in past month }\end{array}$ & - & $1.37^{* *}(1.08$ to 1.74$)$ & $1.32^{*}$ (1.03 to 1.69$)$ & 1.21 (0.97 to 1.50$)$ & - \\
\hline $\begin{array}{l}\text { Requested different GHW } \\
\text { in past month }\end{array}$ & 1.46 (0.93 to 2.28$)$ & $1.57^{*}(1.07$ to 2.30$)$ & 1.49 (0.99 to 2.22 ) & 1.27 (0.89 to 1.82 ) & - \\
\hline \multicolumn{6}{|l|}{ Perceived harm variables } \\
\hline $\begin{array}{l}\text { Believes brands do not } \\
\text { differ in harmfulness }\end{array}$ & 0.96 (0.72 to 1.27 ) & 0.86 (0.68 to 1.10$)$ & - & 0.98 (0.79 to 1.22 ) & - \\
\hline \multicolumn{6}{|c|}{ Balance between enjoyment and concern } \\
\hline More enjoyment & 1.00 & 1.00 & 1.00 & 1.00 & 1.00 \\
\hline Balance & 1.01 (0.70 to 1.46$)$ & 1.18 (0.86 to 1.62 ) & 1.15 (0.82 to 1.62 ) & $1.18(0.90$ to 1.56$)$ & 1.14 (0.85 to 1.52$)$ \\
\hline More concern & 0.91 (0.60 to 1.38 ) & $1.79 * * *$ (1.27 to 2.52$)$ & $1.62 *(1.12$ to 2.34$)$ & $1.43^{*}(1.04$ to 1.96$)$ & 1.31 (0.94 to 1.82$)$ \\
\hline
\end{tabular}

perceived satisfaction after the packaging changes contributed to these quitting-related cognitions and behaviours independently of responses that were more closely tied to the new GHWs.

Although caution must be exercised when interpreting findings that were not part of a systematic pattern of effects and were not significant in the multivariable models, we do note that two of the findings in the initial models were in an unexpected direction and are difficult to explain (negative associations between believing that brands do not differ in prestige/ harmfulness and quit attempts). It may be that these appeal and perceived harm variables operate in different ways for different smokers, influenced by factors such as the brand and variant they smoke (eg, cigarettes from premium, mainstream or value brand segments) and their history with that brand. It is also possible that the impact of these beliefs may be moderated by responses to the GHWs. Furthermore, it is possible that the predictive effects observed in this study are different for different demographic subgroups, particularly given that Wakefield et al ${ }^{4}$ found greater change on the appeal variables for younger than older adult smokers. Further research is required to investigate the possibility that the predictive effects observed in this study may be conditional on demographic and smoker characteristics.

It is possible that the variables measured in this study are related to each other in more complex ways. ${ }^{32}$ For example, one recent study identified a series of mediational pathways through which health warnings lead to quit attempts, ${ }^{12}$ while another used structural equation models to explore associations between aspects of cigarette and cigarette packaging appeal, and cigarette consumption and quit attempts. ${ }^{33}$ In addition, longitudinal studies have established that quitting-related cognitions and microindicators of concern predict attempts to quit. ${ }^{17} 34-37$ Studies that more thoroughly investigate the pathways through which PP and GHW policies lead to changes in smoking behaviours are critical.

A particular strength of this study is the use of a cohort design, with a good retention rate and a nationally representative sample. In these analyses, respondents acted as their own control, allowing us to minimise the influence of unobserved individual differences and any time-invariant response biases. While these analyses provide some confidence that the proposed causal order between variables is the correct one, further 
Table 4 Associations between appeal, health warning effectiveness, perceived harm and enjoyment/concern variables measured at baseline, and quit attempts measured at 1-month follow-up among baseline cigarette smokers

\begin{tabular}{|c|c|c|}
\hline & $\begin{array}{l}\text { Initial models } \\
(\mathrm{N}=2726 \text { to } 3116)\end{array}$ & $\begin{array}{l}\text { Multivariable model } \\
(\mathrm{N}=2964)\end{array}$ \\
\hline & OR $(95 \% \mathrm{Cl})$ & OR $(95 \% \mathrm{Cl})$ \\
\hline \multicolumn{3}{|l|}{ Appeal variables } \\
\hline Dislikes pack & 0.89 (0.66 to 1.20$)$ & - \\
\hline Lower pack appeal & 1.04 (0.83 to 1.30$)$ & - \\
\hline Lower quality & 1.22 (0.96 to 1.56$)$ & - \\
\hline Lower satisfaction & 1.12 (0.87 to 1.45$)$ & - \\
\hline Lower value for money & 1.03 (0.83 to 1.29$)$ & - \\
\hline Believes brands do not differ in prestige & $0.79 *(0.64$ to 0.98$)$ & $0.88(0.70$ to 1.10$)$ \\
\hline \multicolumn{3}{|l|}{ Health warning effectiveness variables } \\
\hline Notices GHW first when looking at pack & 1.05 (0.83 to 1.33 ) & - \\
\hline Does not believe dangers of smoking are exaggerated & 0.98 (0.78 to 1.23$)$ & - \\
\hline Attributes much more motivation to quit to GHWs & $2.31 * * *(1.73$ to 3.09$)$ & $2.15^{* * *}(1.59$ to 2.91$)$ \\
\hline Concealed pack in past month & 1.20 (0.94 to 1.52$)$ & - \\
\hline Requested different GHW in past month & $2.04^{* * *}(1.43$ to 2.89$)$ & $1.88^{* * *}(1.30$ to 2.71$)$ \\
\hline \multicolumn{3}{|l|}{ Perceived harm variables } \\
\hline Believes brands do not differ in harmfulness & $0.78 *(0.62$ to 0.99$)$ & 0.86 (0.68 to 1.09$)$ \\
\hline \multicolumn{3}{|l|}{ Balance between enjoyment and concern } \\
\hline More enjoyment & 1.00 & - \\
\hline Balance & 0.98 (0.72 to 1.34$)$ & \\
\hline More concern & 1.40 (0.99 to 1.99$)$ & \\
\hline \multicolumn{3}{|c|}{$\begin{array}{l}\text { Bolded results are statistically significant at } p<0.05 \text {. The weighted } \mathrm{N} \text { per initial model varies due to missing data on the outcome variable and predictor variables. The weighted } \mathrm{N} \text { for } \\
\text { the multivariable model includes only those cases with valid data on the outcome variable and all of the predictor variables included in the model. All models adjust for recency of the } \\
\text { last quit attempt made at baseline and for: date of the follow-up survey; number of days between baseline and follow-up survey; cumulative Target Audience Rating Points } \\
\text { (antismoking television advertising) in the } 3 \text { months prior to the follow-up survey; change in cigarette costliness (based on month of the follow-up survey); sex; age; education; } \\
\text { socioeconomic status and Heaviness of Smoking Index (measured at baseline). -Predictor variable not included in multivariable model due to non-significant (at } p<0.05 \text { ) association } \\
\text { with outcome variable in initial model. } \\
* * * p^{*} \leq 0.001,{ }^{* *} p<0.01,{ }^{*} p<0.05 \text {. } \\
\text { GHW, graphic health warning. }\end{array}$} \\
\hline
\end{tabular}

mediation analyses and controlled experimental studies are required to establish if the appeal, GHW effectiveness, perceived harm and enjoyment/concern variables are causally responsible for the observed changes in quitting-related outcomes. ${ }^{5}$ Nonetheless, the policy relevance of these findings is reinforced by the fact that we controlled for other factors known to predict quitting (antismoking television advertising and changes in cigarette costliness) and also found that the effects were robust to adjustments for seasonality effects and any anticipatory effects related to the December 2013 tax increase. The short duration of the 1-month follow-up period meant that we were unable to fairly assess rates of sustained quitting and engagement in other behaviours that smokers may use to circumvent heightened feelings of risk, including switching products or reducing daily cigarette consumption. These low incidence outcomes would be better assessed in longer term cohort studies.

Overall, the current findings strengthen the evidence base for PP with larger GHWs by demonstrating that quitting-related cognitions and behaviours are prospectively predicted by the more proximal beliefs and perceptions widely used as outcome measures in the experimental and naturalistic studies that helped make the case for PP. ${ }^{10} 1138$ Our findings suggest that, among adults, increased GHW effectiveness is likely to be particularly influential in driving quitting behaviour. As such, these results contrast with study findings of adolescents, where implementation of the new packaging was found to lead adolescents to have fewer favourable and more unfavourable perceptions of cigarette packs, ${ }^{39}$ with little evidence that the new GHWs had an effect. ${ }^{40}$ However, our understanding of the role that the appeal of cigarettes and cigarette packaging plays in influencing adult smoking behaviour may be improved by further examining interactive relationships between the appeal, GHW effectiveness and perceived harm variables, and by testing whether these effects are conditional on smoker characteristics.

\section{What this paper adds}

- This is the first study to examine whether the proximal measures of plain packaging with larger and refreshed graphic health warning effectiveness-measures of appeal, graphic health warning effectiveness and perceived harmpredict subsequent changes in quitting-related cognitions and behaviours.

- Using a prospective cohort study with a nationally representative sample of Australian adult cigarette smokers surveyed within the first year of plain packaging, we found increased graphic health warning effectiveness to be particularly influential in driving adult quitting cognitions and behaviour, some influence for select appeal variables and no contribution from accurate harm perceptions.

- These findings provide initial insight into the mechanisms through which plain packaging with larger and refreshed graphic health warnings is likely to bring about changes in smoking behaviours.

Acknowledgements The authors thank Professor Ron Borland for sharing questions from the ITC survey for inclusion in the telephone tracking survey, the Social Research Centre for data collection and Megan Bayly and Emily Bain for data checking. 
Contributors MW designed the study. $\mathrm{KC}$ and MZ managed the data collection and cleaned the data files. EB and SD analysed the data and interpreted the results. EB drafted the manuscript with contributions from all authors. All authors approved the final manuscript.

Funding The National Plain Packaging Tracking Survey was funded under a contract with the Australian Government Department of Health and Ageing.

Competing interests The authors wish to advise that MW was a member and MS a technical writer for the Tobacco Working Group of the Australian National Preventive Health Task Force and MW was a member of the Expert Advisory Committee on Plain Packaging that advised the Australian Department of Health on research pertaining to the plain packaging legislation. MW, SD and EB hold competitive grant funding from the Australian National Health and Medical Research Council and MW holds competitive grant funding from the US National Institutes of Health, Australian National Preventive Health Agency and BUPA Health Foundation.

Ethics approval The survey was approved by the Cancer Council Victoria Human Ethics Committee (HREC 0018).

Provenance and peer review Not commissioned; externally peer reviewed.

Open Access This is an Open Access article distributed in accordance with the Creative Commons Attribution Non Commercial (CC BY-NC 4.0) license, which permits others to distribute, remix, adapt, build upon this work non-commercially, and license their derivative works on different terms, provided the original work is properly cited and the use is non-commercial. See: http://creativecommons.org/ licenses/by-nc/4.0/

\section{REFERENCES}

1 Tobacco Plain Packaging Act. No. 148, 2011 as amended. 2011. http://www. comlaw.gov.au/Details/C2013C00190

2 Scollo M, Lindorff K, Coomber K, et al. Standardised packaging and new enlarged graphic health warnings for tobacco products in Australia-legislative requirements and implementation of the Tobacco Plain Packaging Act 2011 and the Competition and Consumer (Tobacco) Information Standard, 2011. Tob Control 2015;24:ii9-16.

3 Competition and Consumer (Tobacco) Information Standard. F2013C00598. 2011. http://www.comlaw.gov.au/Details/F2013C00598

4 Wakefield M, Coomber K, Zacher M, et al. Australian adult smokers' responses to plain packaging with larger graphic health warnings 1 year after implementation: results from a national cross-sectional tracking survey. Tob Control 2015;24:ii17-25.

5 Durkin S, Brennan E, Coomber K, et al. Short-term changes in quitting-related cognitions and behaviours after the implementation of plain packaging with larger health warnings: findings from a national cohort study with Australian adult smokers. Tob Control 2015;24:ii26-32.

6 Slade J. The pack as advertisement. Tob Control 1997;6:169-70.

7 Wakefield M, Morley C, Horan JK, et al. The cigarette pack as image: new evidence from tobacco industry documents. Tob Control 2002;11:i73-80.

8 National Cancer Institute. The role of the media in promoting and reducing tobacco use. Bethesda, MD: United States Department of Health and Human Services, National Institutes of Health, National Cancer Institute. NIH Pub. No 07-6242, 2008. http://www.cancercontrol.cancer.gov/tcrb/monographs/19/index.html (accessed 18 Sep 2014).

9 U.S. Department of Health and Human Services. Preventing tobacco use among youth and young adults: a report of the Surgeon General. Atlanta, GA: US Department of Health and Human Services, Centers for Disease Control and Prevention, National Center for Chronic Disease Prevention and Health Promotion, Office on Smoking and Health, 2012. http://www.surgeongeneral.gov/library/reports/ preventing-youth-tobacco-use/index.html (accessed 18 Sep 2014).

10 Hammond D. Standardized packaging of tobacco products: evidence review. Prepared on behalf of the Irish Department of Health: March 2014. http://www.drugsandalcohol. ie/22106/1/Standardized-Packaging-of-Tobacco-Products-Evidence-Review.pdf (accessed 18 Sep 2014).

11 Chantler C. Standardised packaging of tobacco. Report of the independent review undertaken by Sir Cyril Chantler. April 2014. http://www.kcl.ac.uk/health/ packaging-review.aspx (accessed 18 Sep 2014).

12 Yong HH, Borland R, Thrasher JF, et al. Mediational pathways of the impact of cigarette warning labels on quit attempts. Health Psychol 2014;33:1410-20.

13 Huang J, Chaloupka FJ, Fong GT. Cigarette graphic warning labels and smoking prevalence in Canada: a critical examination and reformulation of the FDA regulatory impact analysis. Tob Control 2014;23:7-12.

14 Coomber K, Zacher M, Durkin S, et al. Australian National Tobacco Plain Packaging Tracking Survey: Technical Report. Melbourne: Cancer Council Victoria and Social Research Centre, December 2014. http://tobaccocontrol.bmj.com/lookup/suppl/ doi:10.1136/tobaccocontrol-2014-052050/-/DC1
15 Partos TR, Borland $\mathrm{R}$, Yong $\mathrm{H}-\mathrm{H}$, et al. The quitting rollercoaster: how recent quitting history affects future cessation outcomes (data from the International Tobacco Control 4-Country Cohort Study). Nicotine Tob Res 2013;15:1578-87.

16 Stillman S. Smoking cessation. Melbourne: Cancer Council Victoria, 2011. http:// www.tobaccoinaustralia.org.au/chapter-7-cessation/7-13-methods-services-andproducts-for-quitting-co (accessed 18 Sep 2014).

17 Vangeli E, Stapleton J, Smit ES, et al. Predictors of attempts to stop smoking and their success in adult general population samples: a systematic review. Addiction 2011;106:2110-21.

18 Australian Bureau of Statistics. Technical paper: socio-economic indexes for areas (SEIFA) 2011. Canberra, Australia: Australian Bureau of Statistics, 2013. http://www.ausstats.abs. gov.au/ausstats/subscriber.nsf/0/22CEDA8038AF7A0DCA257B3B00116E34/\$File/2033. 0.55.001\%20seifa\%202011\%20technical\%20paper.pdf (accessed 18 Sept 2014).

19 Heatherton TF, Kozlowski LT, Frecker RC, et al. Measuring the heaviness of smoking: using self-reported time to the first cigarette of the day and number of cigarettes smoked per day. Br J Addict 1989;84:791-9.

20 Wakefield MA, Spittal MJ, Yong HH, et al. Effects of mass media campaign exposure intensity and durability on quit attempts in a population-based cohort study. Health Educ Res 2011;26:988-97.

21 Dunlop S, Cotter T, Perez D, et al. Televised antismoking advertising: effects of level and duration of exposure. Am J Public Health 2013;103:e66-73.

22 Australian Bureau of Statistics. Average Weekly Earnings, Australia. Canberra, Australia: Australian Bureau of Statistics, 2013. 6302.0. http://www.abs.gov.au/ ausstats/abs@.nsf/mf/6302.0 (accessed 18 Sep 2014).

23 Durkin S, Wakefield MA, Spittal MJ. Which types of televised anti-tobacco campaigns prompt more quitline calls from disadvantaged groups? Health Educ Res 2011;26:998-1009.

24 StataCorp. Stata Statistical Software: Release 12. College Station, TX: StataCorp LP: 2011.

25 Hammond D. Health warning messages on tobacco products: a review. Tob Control 2011;20:327-37

26 Institute for Global Tobacco Control. State of evidence review: health warning labels on tobacco products. Baltimore, MD: Johns Hopkins Bloomberg School of Public Health, 2013. http://globaltobaccocontrol.org/sites/default/files/HealthWarnings_ state_of_evidence_final_11_18_2013_web_0.pdf (accessed 18 Sep 2014).

27 Munafo MR, Roberts N, Bauld L, et al. Plain packaging increases visual attention to health warnings on cigarette packs in non-smokers and weekly smokers but not daily smokers. Addiction 2011;106:1505-10.

28 Hoek J, Wong C, Gendall P, et al. Effects of dissuasive packaging on young adult smokers. Tob Control 2011;20:183-8.

29 Wakefield M, Germain D, Durkin S, et al. Do larger pictorial health warnings diminish the need for plain packaging of cigarettes? Addiction 2012;107:1159-67.

30 Al-Hamdani M. The effect of cigarette plain packaging on individuals' health warning recall. Healthcare Policy 2013;8:68-77.

31 Moodie CS, Mackintosh AM. Young adult women smokers' response to using plain cigarette packaging: a naturalistic approach. BMJ Open 2013;3:e002402.

32 International Agency for Research on Cancer. Methods for evaluating tobacco control policies. Lyon, France: International Agency for Research on Cancer, 2008.

33 Ayo-Yusuf OA, Agaku IT. The association between smokers' perceived importance of the appearance of cigarettes/cigarette packs and "Smoking Sensory Experience": a structural equation model. Nicotine Tob Res 2015;17:91-7.

34 Borland $\mathrm{R}$, Yong $\mathrm{HH}$, Wilson $\mathrm{N}$, et al. How reactions to cigarette packet health warnings influence quitting: findings from the ITC Four-Country survey. Addiction 2009;104:669-75.

35 Borland $\mathrm{R}$, Yong $\mathrm{HH}$, Balmford J, et al. Motivational factors predict quit attempts but not maintenance of smoking cessation: findings from the International Tobacco Control Four country project. Nicotine Tob Res 2010;12:S4-S11.

36 Hyland A, Borland R, Li Q, et al. Individual-level predictors of cessation behaviours among participants in the International Tobacco Control (ITC) Four Country Survey. Tob Control 2006;15:iii83-94.

37 Li L, Borland R, Fong GT, et al. Smoking-related thoughts and microbehaviours, and their predictive power for quitting: findings from the International Tobacco Control (ITC) China Survey. Tob Control Published Online First: 25 Feb 2014. doi:10.1136/ tobaccocontrol-2013-051384

38 Stead M, Moodie C, Angus K, et al. Is consumer response to plain/standardised tobacco packaging consistent with Framework Convention on Tobacco Control guidelines? A systematic review of quantitative studies. PLOS ONE 2013;8:e75919.

39 White V, Williams T, Wakefield M. Has the introduction of plain packaging with larger graphic health warnings changed adolescents' perceptions of cigarette packs and brands? Tob Control 2015;24:ii42-9.

40 White $\mathrm{V}$, Williams T, Faulkner A, et al. Do larger graphic health warnings on standardised cigarette packs increase adolescents' cognitive processing of consumer health information and beliefs about smoking-related harms? Tob Control 2015;24: ii50-7. 